\title{
LM04 Functions As a Negative Regulator of Sensory Organ Formation in the Mammalian Cochlea
}

\author{
Min Deng, ${ }^{1 \star}$ Xiong-jian Luo, ${ }^{2 \star}$ Ling Pan, ${ }^{1}$ Hua Yang, ${ }^{1}$ Xiaoling Xie, ${ }^{1}$ Guoqing Liang, ${ }^{3}$ Liang Huang, ${ }^{1,4}$ Fang Hu,, 14 \\ Amy E. Kiernan, ${ }^{1}$ and Lin Gan ${ }^{1,3}$ \\ ${ }^{1}$ Flaum Eye Institute and Department of Ophthalmology, University of Rochester, Rochester, New York 14642, ${ }^{2}$ Key Laboratory of Animal Models and \\ Human Disease Mechanisms of the Chinese Academy of Sciences and Yunnan Province, Kunming Institute of Zoology, Kunming, Yunnan 650223, China, \\ ${ }^{3}$ College of Life and Environmental Sciences, Hangzhou Normal University, Hangzhou, Zhejiang 310036, China, and ${ }^{4}$ Gannan Medical University, Ganzhou, \\ Jiangxi 341000, China
}

In mammals, formation of the auditory sensory organ (the organ of Corti) is restricted to a specialized area of the cochlea. However, the molecular mechanisms limiting sensory formation to this discrete region in the ventral cochlear duct are not well understood, nor is it known whether other regions of the cochlea have the competence to form the organ of Corti. Here we identify LMO4, a LIM-domain-only nuclear protein, as a negative regulator of sensory organ formation in the cochlea. Inactivation of $L m o 4$ in mice leads to an ectopic organ of Corti (eOC) located in the lateral cochlea. The eOC retains the features of the native organ, including inner and outer hair cells, supporting cells, and other nonsensory specialized cell types. However, the eOC shows an orientation opposite to the native organ, such that the eOC appears as a mirror-image duplication to the native organ of Corti. These data demonstrate a novel sensory competent region in the lateral cochlear duct that is regulated by LMO4 and may be amenable to therapeutic manipulation.

Key words: inner ear development; LIM-domain; LM04; organ of Corti; cochlea; transcriptional regulator

\section{Introduction}

Unlike the sensory regions in fish, amphibians, and birds, loss of mammalian cochlear hair cells and supporting cells causes permanent hearing deficits due to the inability of the sensory cells to spontaneously regenerate. The mammalian organ of Corti (OC) has a unique structure, in which the hair cells and supporting cells are arrayed in a tightly organized pattern composed of rows of hair cells and intervening supporting cells. Although considerable inroads have been made in understanding the molecular mechanisms that induce sensory or hair cell formation in the ear (Bermingham et al., 1999; Zheng and Gao, 2000; Mizutari et al., 2013), the factors that regulate OC formation in the cochlea are largely unknown.

Previously, we reported that the LMO family of nuclear proteins LMO1, LMO3, and LMO4 are expressed in the developing inner ear in temporally and spatially distinct regions (Deng et al.,

Received Jan. 26, 2014; revised June 17, 2014; accepted June 19, 2014.

Author contributions: M.D. and L.G. designed research; M.D., X.-j.L., L.P., H.Y., X.X., G.L., L.H., and F.H. performed research; M.D. and L.G. contributed unpublished reagents/analytic tools; M.D., X.-j.L., L.P., H.Y., X.X., A.E.K., and L.G. analyzed data; M.D., X.-j.L., A.E.K., and L.G. wrote the paper.

This work was supported by the National Institute of Health Grants to L.G. (DC008856) and A.E.K. (DC009250), and to L.G. from the National Natural Science Foundation of China Grant 81271006, and the Research to Prevent Blindness challenge grant to the Department of Ophthalmology at the University of Rochester. We thank Drs Bernd Fritzsch, Richard Libby, Patricia White, and the members of Gan laboratory for their insightful discussions and technical assistance.

The authors declare no competing financial interests.

*M.D. and X.j.L. contributed equally to this work.

Correspondence should be addressed to Lin Gan, 601 Elmwood Avenue, Box 314, Flaum Eye Institute and Department of Ophthalmology, University of Rochester, Rochester, NY 14642. E-mail: lin_gan@urmc.rochester.edu.

DOI:10.1523/JNEUROSCI.0352-14.2014

Copyright $\odot 2014$ the authors $\quad 0270-6474 / 14 / 3410072-06 \$ 15.00 / 0$
2006, 2010). To understand the role of LMO4 in the developing inner ear, we have inactivated it using the lac Z reporter knock-in and conditional knock-out approaches (Deng et al., 2010). Both knock-outs demonstrate a similar phenotype, in which the vestibular region is severely malformed (Deng et al., 2010). The morphogenetic defects are due to the loss of early expression of LMO4 in the lateral portion of the otocyst, leading to early patterning defects (Deng et al., 2010). Nevertheless, cochleae are formed in the Lmo4-null mice, although shorter than the wildtype, allowing an examination of the development of the OC in the absence of LMO4 function.

Here we identify a novel sensory competent region in the lateral cochlear duct that is negatively regulated by Lmo4. We found that Lmo4 is continuously expressed in the developing mouse cochlea and inactivation of Lmo4 in mice leads to the formation an ectopic organ of Corti (eOC) located in the lateral cochlea. Interestingly, the eOC retains the features of the native OC. Structurally, the eOC shows a high degree of similarity with the native OC. More importantly, the eOC contains all cell types that the native OC has, including inner and outer hair cells, supporting cells, and other nonsensory specialized cell types. Our study presents the first case that an $\mathrm{eOC}$ can be regenerated by manipulating the Lmo4 gene, which may have important implications for the treatment of hearing loss.

\section{Materials and Methods}

Mice. Lmo $4^{\text {lac } Z}$ knock-in and the $L m o 4^{\text {loxp }}$ conditional knock-out mice were previously reported (Deng et al., 2010). Noon of the day on which a vaginal plug was observed was designated as embryonic day (E)0.5. All animal procedures used in this study were approved by The University 
Committee of Animal Resources at University of Rochester. All of the experiments were performed in mice of either sex $(n \geq 3$ for each genotype).

$X$-gal staining. To determine the expression pattern of Lmo4-lacZ gene, we used X-Gal staining to detect the activity of $\beta$-galactosidase (Gan et al., 1999). Briefly, embryos of either sex were fixed in $4 \%$ paraformaldehyde (PFA) in PBS ( $\mathrm{pH} 7.2)$ at $4^{\circ} \mathrm{C}$ for $1 \mathrm{~h}$. Whole-mount embryos or $20-\mu \mathrm{m}$-thick cryosections were stained overnight at room temperature with $0.1 \% \mathrm{X}-\mathrm{Gal}, 5 \mathrm{~mm}$ potassium ferricyanide, $5 \mathrm{~mm}$ potassium ferrocyanide, $2 \mathrm{~mm} \mathrm{MgCl}_{2}$ in PBS.

Immunohistochemistry and scanning electron microscopy. Scanning electron microscopy (SEM) experiments were performed as previously described (Deng et al., 2010; Pan et al., 2013). For immunohistochemistry of cryosections, the heads of the embryos of either sex from different stages were fixed in $4 \%$ PFA in PBS for $1 \mathrm{~h}$. After three washes of PBS, the tissues were dehydrated in 20\% sucrose in PBS for overnight, embedded in OCT compound (Tissue-Tek), and cryosectioned at a thickness of 14-20 $\mu \mathrm{m}$. Immunolabeling of the sections was then conducted as previously described (Deng et al., 2010; Luo et al., 2013). For whole mount immunohistochemistry, the inner ears of P5 pups were isolated in PBS and then treated with collagenase $(1 \mathrm{mg} / \mathrm{ml}$; Worthington) and neutral protease ( $1 \mathrm{mg} / \mathrm{ml}$; Worthington) for $8 \mathrm{~min}$ in cold HBSS (Invitrogen). The HBSS solution was replaced by DMEM/F12 (contained 5\% FBS) and incubated for $30 \mathrm{~min}$. The cochlea was then dissected under the dissecting microscope, fixed in $4 \%$ PFA in PBS for $1 \mathrm{~h}$ at $4^{\circ} \mathrm{C}$, and then washed with PBS three times. For immunostaining, the cochlea was permeabilized and blocked in PBS plus $0.1 \%$ Triton X-100, 0.03\% saponin, $10 \%$ horse serum. After incubation for $30 \mathrm{~min}$ at room temperature, primary antibody (diluted in PBS plus $0.1 \%$ Triton X-100, 0.03\% saponin, 3\% horse serum, and $3 \%$ BSA) was added and incubated at $4^{\circ} \mathrm{C}$ overnight. The following day, the cochlea was washed in PBS for $\sim 8 \mathrm{~h}$ (PBS changed every $2 \mathrm{~h}$ ) and incubated with fluorescently labeled secondary antibody at $4^{\circ} \mathrm{C}$ overnight.

The primary antibodies and concentrations used in this study were as follows: rabbit anti-MYO6 (Proteus Biosciences; 1:500), goat anti-SOX2 (Santa Cruz Biotechnology; 1:500), rabbit anti-SOX2 (Millipore; 1:500), rabbit anti-S100A1 (Dako; 1:50), mouse anti-p27kip1 (BD PharMingen; 1:200), goat anti-JAG1 (Santa Cruz Biotechnology; 1:200), rabbit antiP75 (Millipore; 1:100), rabbit anti-pSMAD1/5/8 (Cell Signaling Technology; 1:75), rabbit anti-CASP3 (R\&D Systems; 1:500), and AlexaFluor 488-conjugated phalloidin (Invitrogen; 1:100). AlexaFluor-conjugated secondary antibodies were obtained from Invitrogen and were used at a concentration of 1:1000. Images were captured with a Zeiss 510 META confocal microscope.

In situ hybridization. In situ hybridization was performed as previously described (Yang et al., 2003). Briefly, embryos were dissected in cold PBS and fixed in $4 \%$ paraformaldehyde in PBS for overnight. After cryopreserved in $20 \%$ sucrose for overnight, the embryos were embedded in OCT medium (Tissue-Tek) and frozen with dry ice quickly. Tissues were sectioned at $20 \mu \mathrm{m}$ and mRNA expression was detected with digoxigenin-labeled riboprobes specific for Bmp4 (a gift from Dr James F. Martin, Baylor College of Medicine, Houston, TX), Fgf8, Hes5, Jag2 (a gift from Dr Rulang Jiang, Cincinnati Children Hospital, Cincinnati, $\mathrm{OH}$ ), Lfng and Ped (a gift from Dr Doris K. Wu, NIH, Bethesda, MD), Lmo3, Lmo 4 (a gift from Dr Terence H. Rabbitts, University of Oxford, Oxford, United Kingdom), Atoh1, Ped, and Sox2.

\section{Results}

We first investigated the detailed spatiotemporal expression pattern of Lmo4 in the developing mouse cochlea using a lacZ reporter gene knock-in at Lmo4 locus (Lmo4-lacZ) (Deng et al., 2010). Before the sensory formation at E12.5-E13.5, Lmo4-lacZ was broadly expressed in the ventral portion of the cochlea (Fig. $1 A, B)$, including the Sox2-expressing presumptive prosensory domain (Fig. $1 F, G$ ). From E14.5, the expression of Lmo4 is downregulated in the developing OC (Fig. $1 C-E$ ), which is marked by Atoh1 expression (Fig. $1 H-J$ ). Lmo4-lacZ expression was confined in two specific regions in the cochlea: the greater
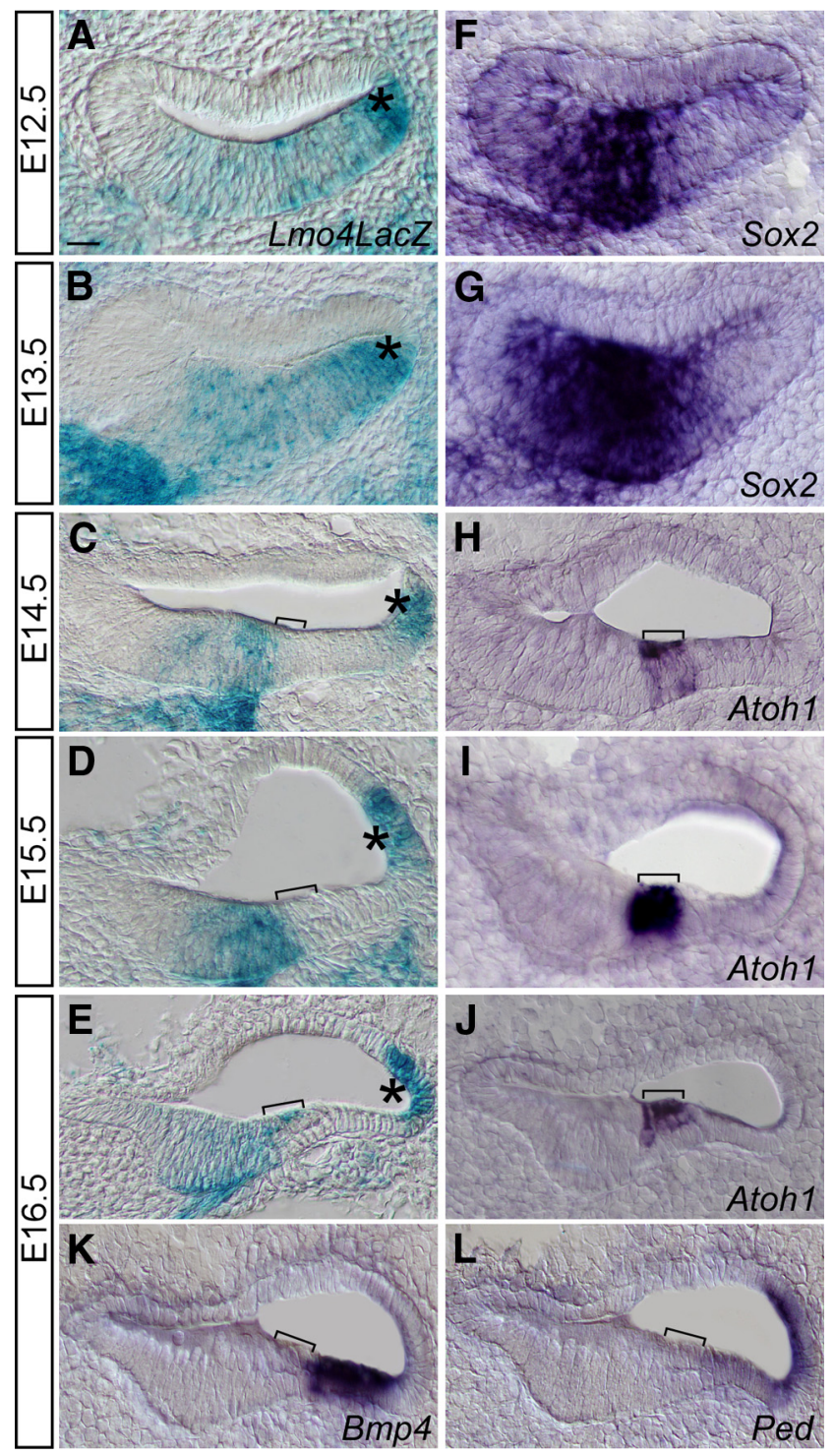

Figure 1. Lmo4 is continuously expressed in the developing mouse cochlea, with a region-

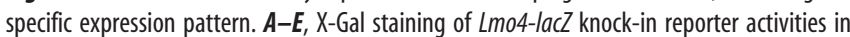
$L m o 4^{l a c z /+}$ cochlea sections reveals the spatiotemporal expression pattern of $L m 04$ in the developing mouse cochlea. $\boldsymbol{F}-\boldsymbol{L}$, In situ hybridization with region-specific markers confirms the spatiotemporal expression pattern of $L m 04$ in the developing mouse cochlear duct. Brackets indicate the OC. Note Lmo4 is continuously expressed in the ES at high level (asterisks in $\boldsymbol{A}-\boldsymbol{E}$ ). Scale bar, $50 \mu \mathrm{m}$.

epithelium ridge (GER) adjacent to the OC and the external sulcus (ES) lateral to the lesser epithelium ridge (LER; Fig. 1C). The specific expression of $\mathrm{Lmo}_{\mathrm{H}}$ in these two regions was maintained after OC formation until at least E16.5 (Fig. 1D,E). The expression of Lmo4 in the ES region was further confirmed by comparing with the expression of $B m p 4$, a marker for the LER region and Pendrin (Ped), a marker of the ES region (Yoshino et al., 2004, 2006). Lmo4 is coexpressed with Ped in the ES region but not with $B m p 4$ at E16.5 (Fig. $1 E, K, L$ ). Later at E16.5, the expression of Lmo4 is detected in hair cells marked by Atoh1 expression (Fig. $1 E, J)$. Together, these results indicate that Lmo4 is continuously expressed in the developing mouse cochlea, with a region-specific expression pattern.

We then characterized the function of LMO4 in the development of mouse cochlea by examining both a traditional knockout and a conditional knock-out (Foxg1-Cre; Lmo4 ${ }^{\text {loxP/loxP }}$ ). 


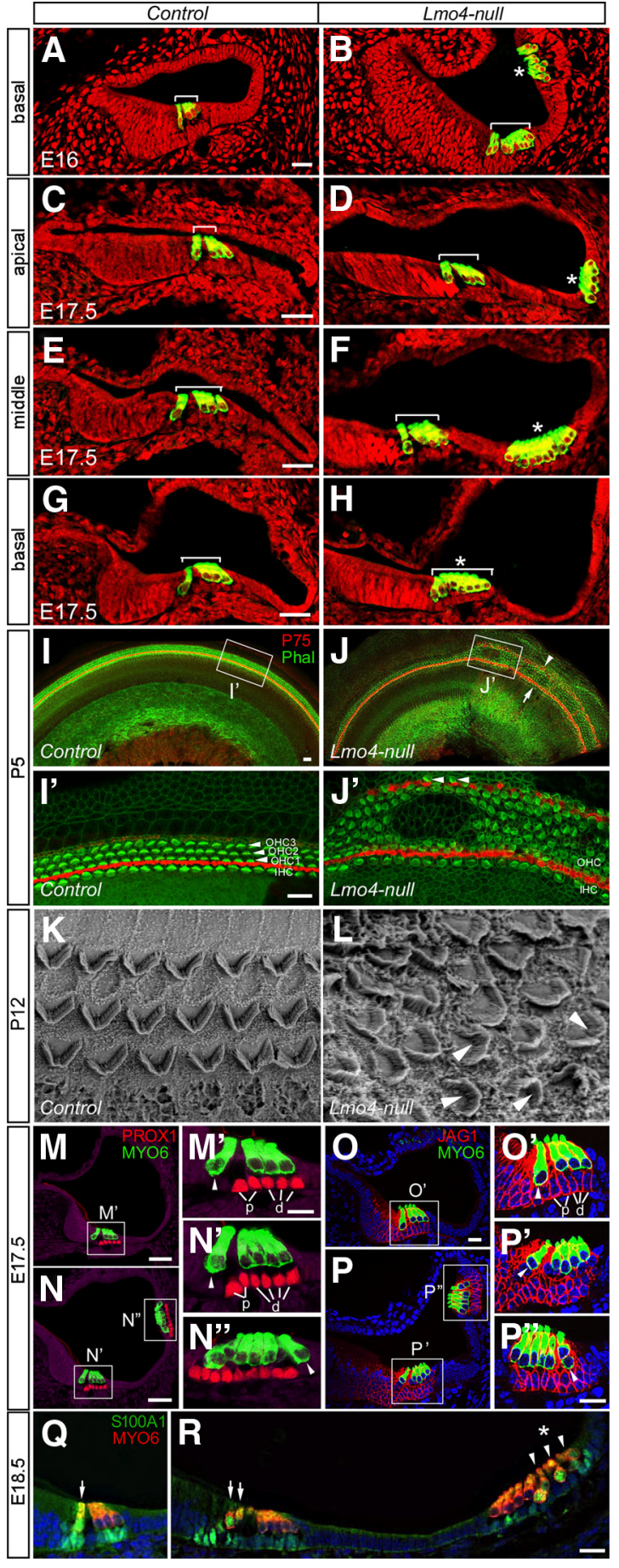

Figure 2. Formation of an ectopic organ of Corti in the Lmo4-null cochlea. $\mathbf{A}-\boldsymbol{H}$, Ectopic hair cells are observed in Lm04-null cochlea. Cross-sections through the indicated turns of the cochlea duct were immunolabeled with anti-MY06 (green) and nuclear counterstained with propidium iodide (red). Brackets indicate the native $0 C$, which contains one row of inner hair cells and three rows of outer hair cells. Asterisks indicate the ectopic hair cells. I-J', Ectopic hair cells and pillar cells are formed in the Lmo4-null cochlea. Whole-mount immunocytochemistry using anti-P75 (red) and FITC-conjugated phalloidin (green) reveals the formation of eOC in the $L$ mo4-null cochlea. $I$ ' and $J$ ' are higher-magnification images of $I$ and $J$, respectively. Arrow and arrowhead in $J$ indicates pillar cells in the native $0 \mathrm{C}$ and $\mathrm{e} O \mathrm{C}$. Arrowheads in $I^{\prime}$ indicate outer hair cells in control cochlea. Arrowheads in $\boldsymbol{J}^{\prime}$ indicate ectopic inner hair cells in the eOC. $\boldsymbol{K}, \boldsymbol{L}$, SEM image shows that planar cell polarity of hair cells is affected in Lmo4-null cochlea. Arrowheads show that the orientation of hair cell stereocilia in the region of ectopic hair cell formation is disrupted in $\mathbf{L}$ mo4-null cochlea. $\boldsymbol{M}-\boldsymbol{P}^{\prime \prime}$, The $\mathbf{L m o 4}$-null cochlea contains an ectopic and reverse orientated OC. Compared with the control $(\boldsymbol{M}, \mathbf{0})$, immunolabeling of the Lmo4-null cochlea ( $\boldsymbol{N}$, P) with anti-MY06 (green) and anti-PROX1 or anti-JAG1 (red) at E17.5 shows the formation of
Compared with the wild-type control (Fig. 2A), ectopic hair cells were detected at the basal turns of the Lmo4-null cochlea at E16 (Fig. 2B, asterisk). By E17.5, this region of hair cells appeared in the middle and apical regions of the lateral cochlea (Fig. 2C-H). Subsequently, the two regions of hair cells merge together to form an expanded domain of hair cells (Fig. $2 \mathrm{H}$ ), perhaps due to apoptosis of intervening cells.

By postnatal day $(\mathrm{P}) 5$, expanded regions of hair cells were present in the middle and apical regions of the cochlea, which sometimes include two domains of hair cells, separated by a small island of nonsensory cells (Fig. 2I, J, $I^{\prime}, J^{\prime}$ ). Compared with one row of P75-positive pillar cells seen in the control cochlea, an ectopic row of pillar cells (arrowhead) was observed in the Lmo4null cochlea in addition to the normal row of the pillar cells (Fig. $2 J$, arrow) seen in the middle turn of the cochlea duct. Interestingly, the ectopic hair cells appeared disorganized within the plane. We therefore asked whether the planar cell polarity (PCP) of hair cells was affected in Lmo4-null cochlea using SEM. In wild-type controls, hair cells were orderly arranged and all the stereocilia of the outer hair cells point in the same direction (Fig. $2 \mathrm{~K}$ ). In Lmo4-null mice, the orientation of hair cells in the region of ectopic hair cell formation was disrupted (Fig. $2 L$ ). Compared with normal PCP observed in the wild-type controls, the PCP of hair cells was disrupted in Lmo4-null mice and the stereocilia of outer hair cells pointed randomly and irregularly in the region of ectopic hair cell formation (Fig. $2 L$ ), which presumably results from the high hair cell density in the shortened Lmo4-null cochlea.

Structurally, the ectopic region of hair cells resembles the native OC (Fig. $2 A-H$, brackets). We then characterized this ectopic region of hair cells using markers for hair cells, supporting cells, and other cochlear regions. We found the ectopic region expressed well characterized hair cell markers, including MYO6, phalloidin, Atoh1, and Jag2 (Figs. $2 B, D, F, H, M-P^{\prime \prime} ; 3 A-B^{\prime}$ ). Analysis of S100A1 expression, which marks inner hair cells as well as supporting cells (Dieter's cells and inner phalangeal cells; Woods et al., 2004; Kiernan et al., 2006), identified inner hair cells on the lateral side of the ectopic region (Fig. 2Q,R). Moreover, Fgf8 expression, which marks inner hair cells (Pirvola et al., 2002; Shim et al., 2005), revealed the Fgf8-expressing inner hair cells in the dorsolateral region of the cochlea, confirming that the ectopic region also contains inner hair cells (Fig. $3 C, C^{\prime}$ ). By comparing the location of $\mathrm{Fg} f 8$ expression with $\mathrm{Jag} 2$ expression, it appeared the ectopic Fgf8-expressing inner hair cell was located on the lateral rather than medial side of the ectopic sensory region.

We next sought to determine whether supporting cells were formed in this ectopic region. Using a number of supporting cell markers, we demonstrated that supporting cells are present in the ectopic region and they express the appropriate markers that are normally expressed in the OC region, including P75, PROX1, JAG1, Hes5, and Lfng (Figs. 2I-J', $M-P^{\prime \prime} ; 3 D-E^{\prime}$ ). Unlike JAG1, Hes5, and Lfng, which are expressed in all OC supporting cells, P75 is uniquely expressed in pillar cells (Mueller et al., 2002; Doetzlhofer et al., 2009), which are specialized supporting cells that separate the inner and outer hair cells. We examined P75

$\leftarrow$

an $\mathrm{e} O \mathrm{C}$ completed with hair cells and supporting cells. Arrowheads indicate the inner hair cells. $\boldsymbol{Q}, \boldsymbol{R}$, Cross-sections through the control $(\boldsymbol{Q})$ and $L$ m04-null $(\boldsymbol{R})$ cochlea at E18.5 stained for MY06 (red), S100A1 (green), and DAPI (blue) confirms that the ectopic region is oriented as a mirror image to the native organ. Arrowheads indicate the inner hair cells in the $\mathrm{e} O \mathrm{C}$ and arrows show inner hair cells in the native 0 C. Scale bars: $A-H, I^{\prime}, J^{\prime}, M, N, 50 \mu \mathrm{m} ; \boldsymbol{I}, J, 200 \mu \mathrm{m} ; \boldsymbol{M}^{\prime}, \boldsymbol{N}^{\prime}$, $\mathbf{N}^{\prime \prime}, \mathbf{O}^{\prime}, \boldsymbol{P}^{\prime}, \boldsymbol{P}^{\prime \prime}, \mathbf{Q}, \mathbf{R}, 20 \mu \mathrm{m}$. 


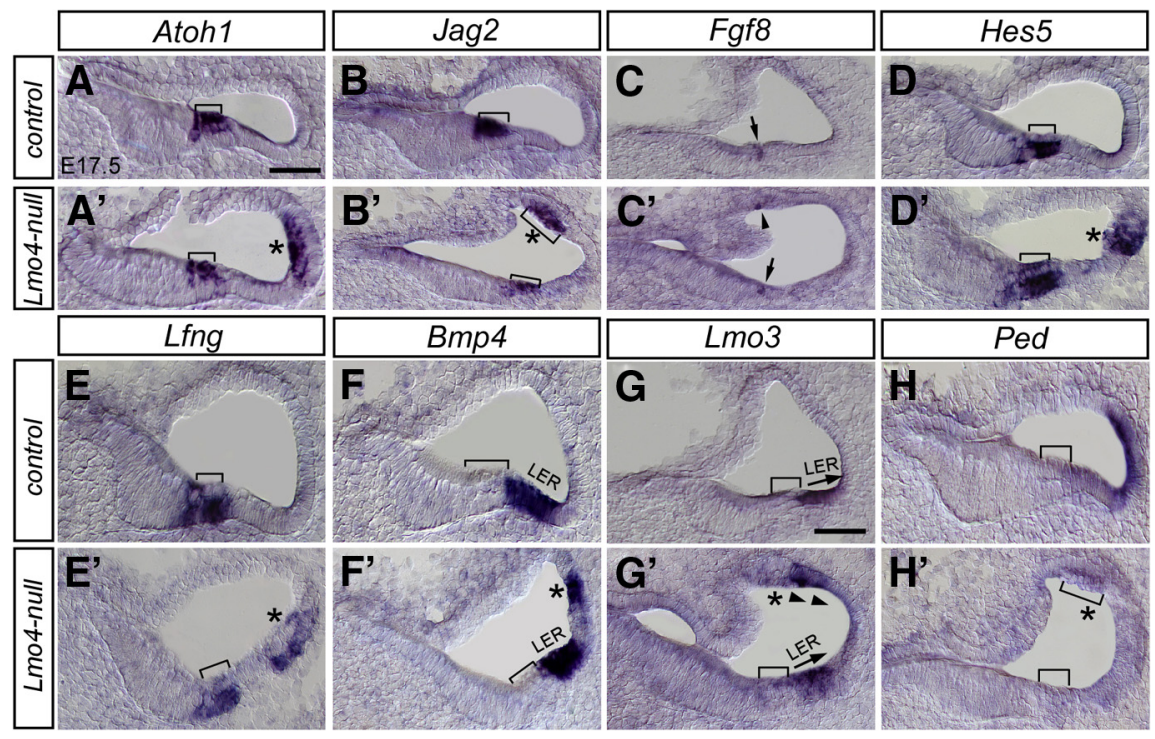

Figure 3. The e 0 C expresses the appropriate hair cell and supporting cell markers. In situ hybridization of $\mathrm{E} 17.5$ cochlea sections at E17.5 with indicated cellular markers. $\boldsymbol{A}-\boldsymbol{C}^{\prime}$, The e0C in the Lmo4-null cochlea expresses hair cell markers (Atoh1 and Jag2) and inner hair cell marker (Fgf8). Brackets show the normal 0 C and asterisks indicate the $\mathrm{e} O \mathrm{C}$. Arrows in $\boldsymbol{C}$ and $\boldsymbol{C}^{\prime}$ show the inner hair cell. Arrowhead in $\boldsymbol{C}^{\prime}$ shows the inner hair cell in the eOC. $\boldsymbol{D}-\boldsymbol{E}^{\prime}$, Supporting cell markers, Hes 5 and $L f$ ng, are expressed in the e $0 C$. $\boldsymbol{F}-\mathbf{G}^{\prime}, B m p 4$ and $L m 03$ expression identifies a second LER region adjacent to the e $O C$ in the $L m 04$-null cochlea, suggesting that not only is the $O C$ duplicated, but also the surrounding LER region. Arrows in $\mathbf{G}$ and $\mathbf{G}^{\prime}$ indicate opposite orientation of the LER in the native $O C$ and eOC. $\boldsymbol{H}, H^{\prime}$, The expression of Ped was lost in the Lmo4-null cochlea, indicating an ES to OC conversion in Lmo4-null cochlea. Scale bar, $50 \mu \mathrm{m}$.

expression in whole mount cochleae using phalloidin to mark the hair cells at P5. We found that the Lmo4-null mutants had a duplicated domain of P75 expression in the middle and apical turns of the cochlea (Fig. $2 I-J^{\prime}$ ). The extra domain was located on the nonmodiolar (lateral) side of the cochlea, with most of the hair cells lying between the normal and ectopic domain (Fig. $2 J^{\prime}$ ), indicating that the ectopic sensory region contains pillar cells. Together, our results demonstrate the formation of an eOC completed with hair cells and supporting cells in the Lmo4-null cochlea and that the eOC is generated in an opposite orientation to the native OC.

We also examined selective regional markers outside the OC, such as Bmp 4 and Lmo3, both markers for the LER region that lies immediately distal to the OC on the nonmodiolar side. Both of these genes show a duplicated region of expression in the lateral cochlea (Fig. $3 F-G^{\prime}$ ), suggesting that not only is the OC duplicated, but also the surrounding regions. The ectopic LER region lies on the modiolar side to the ectopic sensory region, consistent with its opposite orientation to the native organ. Furthermore, the expression of Ped was lost in the Lmo4-null cochlea (Fig. 3 compare $H$ and $H^{\prime}$ ), indicating an ES to OC conversion in Lmo4-null cochlea. Thus, loss of Lmo4 not only leads to the formation of an eOC as a mirror-image duplication of the native OC, but also the duplication of its immediate surrounding areas in the ES. Considering that, $L m o 4$ is specifically expressed in the GER and ES regions from E14.5, these data also suggest that Lmo4 normally represses sensory formation in the ES region of the cochlea and that loss of Lmo4 leads to eOC formation in the ES.

We then investigated whether the eOC developed in a similar fashion to the native organ, including whether the established prosensory markers, such as SOX2, P27KIP1, and JAG1, were expressed before eOC formation. When examined at E14.5, the developmental time period when all of these markers can be de- tected in the nascent OC, none of these markers demonstrated an ectopic lateral domain. In the control cochlea at E15.5, JAG1 is specifically expressed in the GER, and SOX2 and P27KIP1 are expressed in sensory domain (Fig. 4A-C). However, in the Lmo4-null cochlea, both SOX2 and JAG1 showed an ectopic lateral domain, whereas the P27KIP1 domain was expanded laterally. These ectopic or expanded domains were consistent with the location of the eOC (Fig. $4 A^{\prime}-C^{\prime}$ ). These results demonstrate that the eOC develops similarly to the native organ, albeit in a later and accelerated time frame, because the prosensory markers appear $1 \mathrm{~d}$ after those in the native organ, but the eOC appears to differentiate at approximately the same time as the native organ (Fig. 1).

Previous study has shown that BMP signaling plays a pivotal role in the development of OC (Ohyama et al., 2010). To further explore the potential mechanism underlying the formation of the eOC, we examined the phospho-Smad (pSmad) expression in Lmo4-null cochlea. In wildtype controls, pSmad (pSMAD1/5/8) was specifically expressed in the organ of Corti (marked by SOX2 staining; Fig. 4D-F). Interestingly, in addition to its expression in the native organ of Corti, we found that pSMAD1/5/8 was also expressed in the ectopic organ of Corti (Fig. $4 G-I)$. These results indicate that BMP signaling pathway is activated in the eOC, presumably by the ectopic Bmp4 expression on the modiolar side of the eOC.

\section{Discussion}

The mammalian OC is a highly specialized sensory organ that forms in a discrete ventral region of the cochlea. In this study, for the first time, we have demonstrated the existence of a region in the lateral portion of the mammalian cochlea that is competent to make an OC in the absence of LMO4 function. Previous studies have shown that manipulation of a number of genes and pathways, including Notch, Wnt, Atoh1, Six1, Eya1, and Sox2 (Zheng and Gao, 2000; Kawamoto et al., 2003; Shou et al., 2003; Izumikawa et al., 2005; Cafaro et al., 2007; Hartman et al., 2010; Pan et al., 2010; Jeon et al., 2011; Lin et al., 2011; Ahmed et al., 2012; Chai et al., 2012; Kelly et al., 2012; Yang et al., 2012; Mizutari et al., 2013), can induce the formation of hair cells outside the normal region of the OC. However, in none of these cases has an eOC been induced, complete with its diversity of hair cell types, as well as specialized surrounding cell types. Currently, the specification and patterning of the OC is not well understood, although a number of signaling pathways have been implicated, including FGF, Notch, BMP, Wnt, and SHH (Kelly and Chen, 2009). Our results indicate that a second $\mathrm{OC}$-competent region exists in the lateral region of the Corti, and its formation is normally repressed by LMO4. Moreover, we show that loss of Lmo4 leads to the activation of prosensory markers, such as SOX2, P27KIP1, and JAG1 in the ES region before the formation of the eOC (Fig. $4 A-C^{\prime}$ ), suggesting that LMO4 could function upstream of these prosensory proteins and suppress the formation of the prosensory domain. 
The reverse orientation of the eOC in relation to the endogenous $\mathrm{OC}$ suggests that LMO4 may interact with signaling that originates from a region that lies between the two organs, such as the LER. For example, if a signal arises from the LER that induces OC formation as well as dictating the orientation of the OC, that signal would necessarily lead to two organs on either side of that signal that are mirror images of each other. In comparison, a signal arising from a medial source, such as the GER, to induce and pattern the OC and a lateral competent region would lead to two organs that have similar orientations. A possible candidate for an LER signal is BMP4 (Morsli et al., 1998), as a previous study has suggested that BMP levels are important for OC induction (Ohyama et al., 2010). Here, we show that there is phosphorylated SMAD1/5/8 in the eOC region (Fig. 4G-I), suggesting that LMO4 might normally act to suppress BMP signaling on the lateral side and to specify it into structures such as spiral prominence. In the absence of LMO4, cells in the lateral wall show signs of ectopic responsiveness to BMP signaling, allowing the entire lateral wall to be repatterned as prosensory domain using the same signaling pathways that are normally confined to the native prosensory domain. Intriguingly, we found that the formation of the ectopic prosensory region induces an ectopic region of $\mathrm{Bmp} 4$ expression in the lateral region of cochlea (Fig. $3 F^{\prime}$ ). Thus, an alternative possibility is that during normal development, LMO4 acts to suppress the ectopic domain of Bmp4 expression in the lateral region of cochlea and that the phosphorylation of SMAD1/5/8 in the eOC (Fig. 4G-I) in Lmo4-null mice is secondary to the ectopic production of BMP4. A third possibility is that specification of prosensory domain could precede the specification of the LER region, which in turn influences the differentiation of prosensory domain into the OC.

Although their exact function is unclear, LMO proteins contain two tandem zinc-finger LIM domains for protein-protein interactions but lack the DNA-binding domain typical of LIMhomeodomain (LIM-HD) proteins (Kenny et al., 1998). It has been speculated that LMO proteins could function antagonistically toward LIM-HD proteins by competing for binding to their essential cofactor LDB (LIM-domain binding) proteins. Alternatively, they could function to promote the formation of multimeric transcriptional regulatory complexes by bridging factors, such as basic helixloop-helix and GATA proteins (Joshi et al., 2009). In hematopoiesis, a large DNA-binding complex containing GATA1, LMO2, and LDB1, has been isolated from erythroid cells (Wadman et al., 1997). Furthermore, it has been shown that the interaction of LMO2 and LDB1 within such a complex acts as a negative regulator of erythroid differentiation (Visvader et al., 1997). Interestingly, in the developing cochlea, GATA3 is expressed in the prosensory domain, LER, and the presumptive ES region and is required for the specification of prosensory domain. Targeted deletion of Gata3 in the inner ear significantly impairs the formation of prosensory domain (Luo et al., 2013). Thus, it is conceivable that the expression of GATA3 in the ventral cochlear epithelium (including the ES region) makes it competent to generate prosensory domain but LMO4 inhibits GATA3's role in the ES. More studies are required to resolve these different possibilities and are likely to shed light on the nature, timing, and specificity of the signaling that is required for OC formation in the mammalian cochlea.

\section{References}

Ahmed M, Wong EY, Sun J, Xu J, Wang F, Xu PX (2012) Eyal-Six1 interaction is sufficient to induce hair cell fate in the cochlea by activating Atoh1 expression in cooperation with Sox2. Dev Cell 22:377-390. CrossRef Medline

Bermingham NA, Hassan BA, Price SD, Vollrath MA, Ben-Arie N, Eatock RA, Bellen HJ, Lysakowski A, Zoghbi HY (1999) Math1: an essential gene for the generation of inner ear hair cells. Science 284:1837-1841. CrossRef Medline

Cafaro J, Lee GS, Stone JS (2007) Atoh1 expression defines activated progenitors and differentiating hair cells during avian hair cell regeneration. Dev Dyn 236:156-170. CrossRef Medline

Chai R, Kuo B, Wang T, Liaw EJ, Xia A, Jan TA, Liu Z, Taketo MM, Oghalai JS, Nusse R, Zuo J, Cheng AG (2012) Wnt signaling induces proliferation of sensory precursors in the postnatal mouse cochlea. Proc Natl Acad Sci U S A 109:8167-8172. CrossRef Medline 
Deng M, Pan L, Xie X, Gan L (2006) Differential expression of LIM domainonly (LMO) genes in the developing mouse inner ear. Gene Expr Patterns 6:857-863. CrossRef Medline

Deng M, Pan L, Xie X, Gan L (2010) Requirement for Lmo4 in the vestibular morphogenesis of mouse inner ear. Dev Biol 338:38-49. CrossRef Medline

Doetzlhofer A, Basch ML, Ohyama T, Gessler M, Groves AK, Segil N (2009) Hey2 regulation by FGF provides a Notch-independent mechanism for maintaining pillar cell fate in the organ of Corti. Dev Cell 16:58-69. CrossRef Medline

Gan L, Wang SW, Huang Z, Klein WH (1999) POU domain factor Brn-3b is essential for retinal ganglion cell differentiation and survival but not for initial cell fate specification. Dev Biol 210:469-480. CrossRef Medline

Hartman BH, Reh TA, Bermingham-McDonogh O (2010) Notch signaling specifies prosensory domains via lateral induction in the developing mammalian inner ear. Proc Natl Acad Sci U S A 107:15792-15797. CrossRef Medline

Izumikawa M, Minoda R, Kawamoto K, Abrashkin KA, Swiderski DL, Dolan DF, Brough DE, Raphael Y (2005) Auditory hair cell replacement and hearing improvement by Atohl gene therapy in deaf mammals. Nat Med 11:271-276. CrossRef Medline

Jeon SJ, Fujioka M, Kim SC, Edge AS (2011) Notch signaling alters sensory or neuronal cell fate specification of inner ear stem cells. J Neurosci 31: 8351-8358. CrossRef Medline

Joshi K, Lee S, Lee B, Lee JW, Lee SK (2009) LMO4 controls the balance between excitatory and inhibitory spinal V2 interneurons. Neuron 61: 839-851. CrossRef Medline

Kawamoto K, Ishimoto S, Minoda R, Brough DE, Raphael Y (2003) Math1 gene transfer generates new cochlear hair cells in mature guinea pigs in vivo. J Neurosci 23:4395-4400. Medline

Kelly MC, Chen P (2009) Development of form and function in the mammalian cochlea. Curr Opin Neurobiol 19:395-401. CrossRef Medline

Kelly MC, Chang Q, Pan A, Lin X, Chen P (2012) Atoh1 directs the formation of sensory mosaics and induces cell proliferation in the postnatal mammalian cochlea in vivo. J Neurosci 32:6699-6710. CrossRef Medline

Kenny DA, Jurata LW, Saga Y, Gill GN (1998) Identification and characterization of LMO4, an LMO gene with a novel pattern of expression during embryogenesis. Proc Natl Acad Sci U S A 95:11257-11262. CrossRef Medline

Kiernan AE, Xu J, Gridley T (2006) The Notch ligand JAG1 is required for sensory progenitor development in the mammalian inner ear. PLoS Genet 2:e4. CrossRef Medline

Lin V, Golub JS, Nguyen TB, Hume CR, Oesterle EC, Stone JS (2011) Inhibition of Notch activity promotes nonmitotic regeneration of hair cells in the adult mouse utricles. J Neurosci 31:15329-15339. CrossRef Medline

Luo XJ, Deng M, Xie X, Huang L, Wang H, Jiang L, Liang G, Hu F, Tieu R, Chen R, Gan L (2013) GATA3 controls the specification of prosensory domain and neuronal survival in the mouse cochlea. Hum Mol Genet 22:3609-3623. CrossRef Medline

Mizutari K, Fujioka M, Hosoya M, Bramhall N, Okano HJ, Okano H, Edge AS (2013) Notch inhibition induces cochlear hair cell regeneration and recovery of hearing after acoustic trauma. Neuron 77:58-69. CrossRef Medline

Morsli H, Choo D, Ryan A, Johnson R, Wu DK (1998) Development of the mouse inner ear and origin of its sensory organs. J Neurosci 18:33273335. Medline
Mueller KL, Jacques BE, Kelley MW (2002) Fibroblast growth factor signaling regulates pillar cell development in the organ of corti. J Neurosci 22:9368-9377. Medline

Ohyama T, Basch ML, Mishina Y, Lyons KM, Segil N, Groves AK (2010) BMP signaling is necessary for patterning the sensory and nonsensory regions of the developing mammalian cochlea. J Neurosci 30:1504415051. CrossRef Medline

Pan W, Jin Y, Stanger B, Kiernan AE (2010) Notch signaling is required for the generation of hair cells and supporting cells in the mammalian inner ear. Proc Natl Acad Sci U S A 107:15798-15803. CrossRef Medline

Pan W, Jin Y, Chen J, Rottier RJ, Steel KP, Kiernan AE (2013) Ectopic expression of activated notch or SOX2 reveals similar and unique roles in the development of the sensory cell progenitors in the mammalian inner ear. J Neurosci 33:16146-16157. CrossRef Medline

Pirvola U, Ylikoski J, Trokovic R, Hébert JM, McConnell SK, Partanen J (2002) FGFR1 is required for the development of the auditory sensory epithelium. Neuron 35:671-680. CrossRef Medline

Shim K, Minowada G, Coling DE, Martin GR (2005) Sprouty2, a mouse deafness gene, regulates cell fate decisions in the auditory sensory epithelium by antagonizing FGF signaling. Dev Cell 8:553-564. CrossRef Medline

Shou J, Zheng JL, Gao WQ (2003) Robust generation of new hair cells in the mature mammalian inner ear by adenoviral expression of Hath1. Mol Cell Neurosci 23:169-179. CrossRef Medline

Visvader JE, Mao X, Fujiwara Y, Hahm K, Orkin SH (1997) The LIM-domain binding protein Ldb1 and its partner LMO2 act as negative regulators of erythroid differentiation. Proc Natl Acad Sci US A 94:13707-13712. CrossRef Medline

Wadman IA, Osada H, Grütz GG, Agulnick AD, Westphal H, Forster A, Rabbitts TH (1997) The LIM-only protein Lmo2 is a bridging molecule assembling an erythroid, DNA-binding complex which includes the TAL1, E47, GATA-1 and Ldb1/NLI proteins. EMBO J 16:3145-3157. CrossRef Medline

Woods C, Montcouquiol M, Kelley MW (2004) Math1 regulates development of the sensory epithelium in the mammalian cochlea. Nat Neurosci 7:1310-1318. CrossRef Medline

Yang SM, Chen W, Guo WW, Jia S, Sun JH, Liu HZ, Young WY, He DZ (2012) Regeneration of stereocilia of hair cells by forced Atoh1 expression in the adult mammalian cochlea. PLoS One 7:e46355. CrossRef Medline

Yang Z, Ding K, Pan L, Deng M, Gan L (2003) Math5 determines the competence state of retinal ganglion cell progenitors. Dev Biol 264:240-254. CrossRef Medline

Yoshino T, Sato E, Nakashima T, Nagashima W, Teranishi MA, Nakayama A, Mori N, Murakami H, Funahashi H, Imai T (2004) The immunohistochemical analysis of pendrin in the mouse inner ear. Hear Res 195:9-16. CrossRef Medline

Yoshino T, Sato E, Nakashima T, Teranishi M, Yamamoto H, Otake H, Mizuno T (2006) Distribution of pendrin in the organ of Corti of mice observed by electron immunomicroscopy. Eur Arch Otorhinolaryngol 263:699-704. CrossRef Medline

Zheng JL, Gao WQ (2000) Overexpression of Math1 induces robust production of extra hair cells in postnatal rat inner ears. Nat Neurosci 3:580 586. CrossRef Medline 